\title{
Validación de las rúbricas como instrumento de evaluación en estudiantes universitarios de la Facultad de Educación de la Universidad nacional del Centro del Perú- UNCP
}

\author{
Tapukuykuna allichay tapukuykunata lulanapa \\ yaćhapakukunawan yaćhana Fakultadćhu - UNCP
}

\author{
Ongantajima ora monkaratagantsi irasi janekijegi \\ sangenaigatsi kara ogomentotsi gigotakaigiri kogatsi \\ irogomeantaige kara - UNCP
}

Recibido: 09 septiembre 2019 Corregido: 20 enero 2020 Aprobado: 15 junio 2020

Ludencino Amador Huamán Huayta

Nacionalidad: Peruana / Filiación: Universidad Nacional del Centro del Perú

Correo:Ihuaman@uncp.edu.pe / Orcid: oooo-0001-8042-9752.

Mario Rudi Hilario Márquez

Nacionalidad: Peruana / Filiación: Universidad Nacional del Centro del Perú

Correo: mhilario@uncp.edu.pe / Orcid: oooo-0003-4052-3263

Yancileide Miluska Franco Cuicapusa

Nacionalidad: Peruana / Filiación: Ministerio de Educación del Perú

Correo:yancileidefc@gmail.com / Orcid:0000-0002-0426-1713

\section{Resumen}

La investigación tiene como propósito validar un grupo de rúbricas como instrumentos de evaluación de procesos y productos del aprendizaje con enfoque de competencias en estudiantes universitarios de la Facultad de Educación - UNCP, enmarcado en el enfoque de evaluación formativa y participativa, en forma analítica e interpretativa. Se analizaron las bases teóricas, metodológicas y experiencias internacionales del diseño, elaboración y validación de las rúbricas, entendidas como una escala valorativa que ofrece descripciones del desempeño de los estudiantes en diferentes criterios a partir de un aumento progresivo de niveles que se corresponden con los indicadores de logro o avance de aprendizaje. Como resultado se presenta la validez y confiabilidad de cinco rúbricas para evaluar: exposición-discusión de trabajos grupales, monografías, ensayos académicos (en pregrado), proyectos de tesis y artículos académicos (en posgrado) mediante la técnica de jueces y los métodos estadísticos. Se concluye que las rúbricas tienen validez y confiabilidad, constituyen una alternativa más cualitativa en valoración de resultados de aprendizaje con enfoque de competencias y pueden utilizarse como instrumentos de autoevaluación, coevaluación y heteroevaluación, para una evaluación participativa y formativa de los estudiantes, porque muestran una tendencia a la autorregulación y mejora.

\section{Palabras clave:}

Rúbricas, niveles de desempeño, evaluación, autoevaluación, coevaluación y heteroevaluación, validez y confiabilidad.

\section{Lisichiku limaykuna:}

tapukuykunap, lulaykunap pataknikuna, tapuna, kikitapukuy, tapunakuy, wayapap walmiptapukuy, allichana, allikayninwan.

\section{Nibarintsipage katingatsaro: monkaramentopage,oakantageti kogantsi,monkaratagantsi, aike omonkaratanëma eiroegi, oganinare aike manëkotagantsi.}




\title{
Validation of rubrics as an assessment instrument in university students of the Faculty of Education of the National University of the Center of Peru- UNCP
}

\begin{abstract}
The objective of the research is to validate a group of rubrics as tools to evaluate learning processes and products with a competence approach in university students of the Faculty of Education - UNCP, framed in the approach of formative and participatory evaluation, in an analytical and interpretative way. We analyzed the theoretical, methodological and international experiences of the design, elaboration and validation of titles, understood as an evaluation scale that provides descriptions of the students' performance in different criteria based on a progressive increase in levels that correspond to the indicators of achievement or progress of learning. As a result, the validity and reliability of five titles to evaluate are presented: exhibition-discussion of group work, monographs, academic essays (at graduation), thesis projects and academic articles (in graduate studies) through the technique of judges and statistical methods. It is concluded that the items have validity and reliability, constitute a more qualitative alternative in the evaluation of learning outcomes with competence approach and can be used as instruments of self-assessment, co-evaluation and heteroavaluation, for participatory and formative evaluation of students, as they tend to self-regulation and improvement.
\end{abstract}

\section{Keywords}

Rubrics, performance

levels, evaluation, self-assessment, co-evaluation and heteroassessment, validity and reliability.

\section{Validação das rubricas como instrumento de avaliação em estudantes universitários do Curso de Educação da Universidade Nacional do centro do Peru- UNCP}

\section{Resumo}

O propósito da pesquisa é validar um grupo de rubricas como instrumentos de avaliação de processos e produtos da aprendizagem com enfoque de competências em universitários do Curso de Educação - UNCP, enquadrados no enfoque da avaliação formativa e participativa, de forma analítica e interpretativa. Foram analisadas as bases teóricas, metodológicas e experiências internacionais do desenho, elaboração e validação das rubricas, entendidas como uma escala valorativa que oferece descrições do desempenho dos estudantes em diferentes critérios a partir de um aumento progressivo dos níveis que se correspondem com os indicadores de alcance ou avance da aprendizagem. Como resultado se apresenta a validade e confiabilidade de cinco rubricas para avaliar: exposição-discussão de trabalhos em grupo, monografias, ensaios acadêmicos (na graduação), projetos de tese e artigos acadêmicos (na pós-graduação) por meio da técnica de juízes e métodos estatísticos. Conclui-se que as rubricas possuem validade e confiabilidade, constituem uma alternativa mais qualitativa na valoração dos resultados da aprendizagem com enfoque de competências e podem ser utilizadas como instrumentos de autoavaliação, coavaliação e heteroavaliação, para uma avaliação participativa e formativa dos alunos, porque apresentam tendência à autorregulação e melhoria.

\section{Palavras-chave:}

Rubricas, níveis

de desempenho, avaliação, autoavaliação, coavaliação e heteroavaliação, validade e confiabilidade.

\section{Datos de los autores}

Ludencino Amador Huamán Huayta, es docente e investigador en Educación, currículo y evaluación, Doctor en Ciencias de la Educación, Evaluador externo del modelo de acreditación por Sineace, Director de departamento académico de la Facultad de Educación - UNCP.

Mario Rudi Hilario Márquez, es docente e investigador en Educación, filosofía y epistemología. Licenciado en Pedagogía y Humanidades, Docente asociado de la Universidad Nacional del Centro del Perú.

Yancileide M. Franco Cuicapusa, es docente e investigadora en educación, con estudios concluidos de maestría en gestión educativa, Licenciada en Educación Primaria. 


\section{Introducción}

El enfoque por competencias se va implementando en los sistemas educativos de muchos países a nivel internacional. Constituye una de las propuestas que "emerge con gran fuerza para lograr una formación auténtica que responda a las exigencias del siglo XXI, e incluso impulsada a través de organismos internacionales (Hernández-Mosqueda, Tobón-Tobón y Guerrero-Rosas, 2016, p. 360). "Muchas universidades en diferentes países están rediseñando sus carreras a través de nuevos perfiles académico-profesionales en los que incluyen una serie de competencias" (Villa y Poblete, 2007, p. 23).

Desde las dos últimas décadas, también en la educación peruana, se viene implementado el enfoque por competencias en la educación básica y superior. Sin embargo, existen muchas dificultades en su manejo teórico y metodológico, sobre todo en la evaluación. Resulta lógico deducir que, si el modelo curricular se desplazó hacia uno basado en competencias, la evaluación deberá seguir la misma línea, sin embargo, el diseño de la evaluación no ha seguido el mismo esfuerzo (Champin, 2014, p. 566).

En la actualidad, generalmente los docentes evalúan las competencias y capacidades según sus concepciones y procedimientos orientados más al aspecto cognoscitivo descuidando los otros aspectos. Muchas universidades se encuentran en tránsito del modelo de objetivos hacia el de competencias en los diseños curriculares y en el desarrollo de las clases; en la evaluación de las competencias se afrontan muchas dificultades; como afirma Valverde J. y Ciudad A. (2014), "es preciso introducir nuevos sistemas de evaluación que mejoren la validez y fiabilidad de los métodos tradicionales e introduzcan en el proceso de evaluación la participación activa del propio estudiante" (p.50).

Cano (2008) plantea que la evaluación por competencias exige utilizar una diversidad de instrumentos e implicar a diferentes agentes. Sugiere tomar muestras de las ejecuciones de los alumnos y utilizar la observación como estrategia de recogida de información sistemática, que puede acompañarse de registros cerrados (check-list, escalas, rúbricas) o de registros abiertos, y puede hacerse por parte del profesorado, por parte de los compañeros o por parte del propio estudiante (o por todos ellos, en un modelo de evaluación de $360^{\circ}$ ), pero en cualquier caso debe proporcionar información sobre la progresión en el desarrollo de la competencia y sugerir caminos de mejora. Por su parte, Tobón (2013) con el enfoque socioformativo propone una metodología, técnicas e instrumentos que pueden facilitar la evaluación de competencias, como portafolios, mapas de aprendizaje, rúbricas, etc. que podrían ser adaptados y aplicados en la evaluación de las asignaturas.

De acuerdo con Rodríguez-Gallego (2014) en el enfoque por competencias, la evaluación auténtica es una excelente alternativa que se adapta a las formas de trabajo requeridas y a los propósitos educativos planteados en planes y programas de estudio en el ámbito universitario, y los instrumentos utilizados son el portafolio y la matriz de valoración o rúbrica, entre otros.

Existe la tendencia a considerar las rúbricas como uno de los instrumentos más recomendables para la evaluación de las competencias; porque es un potente instrumento para la evaluación de cualquier tipo de tarea, permite diseccionar las tareas complejas que conforman una competencia en tareas más simples distribuidas de forma gradual y operativa (Alsina y otros, 2013). 
La rúbrica nace en el seno de una visión constructivista centrada en el aprendiz (Guzmán, Flores y Tirado F., 2012) y se definen como descriptores cualitativos que establecen la naturaleza de un desempeño, son instrumentos en los cuales se establecen criterios y estándares por niveles, mediante la disposición de escalas, que permiten determinar la calidad de la ejecución de los estudiantes en unas tareas específicas; su finalidad es compartir los criterios de realización de las tareas de aprendizaje y de evaluación con los estudiantes y entre el profesorado. Muestra las expectativas que el alumnado y profesorado tienen y comparten sobre una actividad o varias actividades, organizadas en diferentes niveles de cumplimiento: desde el menos aceptable hasta la resolución ejemplar, desde lo considerado como insuficiente hasta lo excelente. Reduce la subjetividad de la evaluación y permite al estudiante monitorizar la propia actividad, autoevaluándose y favoreciendo la responsabilidad ante los aprendizajes (Alsina y otros, 2013; Valverde J. y Ciudad A., 2014; Gatica-Lara F. y Uribarren-Berrueta T., 2013, Ávila y otros 2015).

Para García - Sanz (2014) las rúbricas constituyen un conjunto de criterios de calidad relacionados con la competencia o competencias a evaluar, determinados por descriptores o indicadores que suponen distintos niveles de logro o desempeño de los mismos. Dichos niveles han de poner de manifiesto no sólo el incremento cuantitativo de los estudiantes, sino también el salto cualitativo, es decir, demostrar cuánto han aprendido y lo bien que han aprendido. Pueden ser utilizadas para evaluar competencias u objetivos de aprendizaje, según el contexto y modelo curricular que se trabaje; "es un instrumento de evaluación basado en una escala cuantitativa y/o cualitativa asociada a unos criterios preestablecidos" (Torres y Perera, 2010, p. 142).

En la concepción de la evaluación para el aprendizaje, Ávila y otros (2015) señalan algunas ventajas pedagógicas de las rúbricas:

a) Son un modo eficiente de recopilar información sobre qué saben hacer los estudiantes. Con esto, el profesor puede tomar decisiones pedagógicas concretas: qué contenidos reforzar, cuánta ejercitación hacer, qué tipo de actividades implementar, con qué continuar trabajando, etc.

b) Proveen de retroalimentación efectiva a los estudiantes. En otras palabras, ellos tienen un detalle de los aspectos que lograron y de los que necesitan mejorar.

c) Facilitan la reflexión sobre lo que se está aprendiendo (metacognición), ya que, al delinear claramente los niveles, las dimensiones y los criterios de corrección permiten pensar mejor los aprendizajes. Por esto, son útiles para promover la autoevaluación, la corrección entre pares y la reflexión sobre la escritura.

Complementando a todo ello, Fraile, Pardo y Panadero (2016) precisan algunas características del uso formativo de las rúbricas: transparencia, reducción de la ansiedad, combina acciones metacognitivas y de autorregulación, incrementa la autoeficacia, y es formativo; que generará a su vez una mayor seguridad y confianza por parte del alumnado.

Las rúbricas pueden ser holísticas o sintéticas (no separa las partes de una tarea) y analíticas (evalúa cada parte de una actividad o de un conjunto de actividades) (Alsina, 2013; Ávila y otros, 2015, y Hernández-Mosqueda, Tobón-Tobón y Guerrero-Rosas, 2016). Es un potente instrumento para la evaluación de cualquier tipo de tarea, pero hay que destacar especialmente su valor para evaluar tareas auténticas, tareas de la vida real; se manifiesta como un instrumento idóneo para evaluar competencias, pues permite diseccionar las tareas complejas que conforman una competencia en tareas más simples distribuidas de forma gradual y operativa (Gatica-Lara F. y Uribarren-Berrueta T., 2013). 
En el ámbito internacional, existen propuestas y experiencias sobre evaluación de las competencias en la educación superior, pero son relativamente pocos los estudios acerca del uso y ventajas de las rúbricas. Como afirma Blanco (2011) la investigación educativa sobre las rúbricas es considerablemente reciente; destacándose dos temas al respecto: la calidad técnica como la fiabilidad de las puntuaciones y en menor medida la validez; y sobre el impacto en el aprendizaje y rendimiento de los estudiantes.

Alsina y otros (2013) en un trabajo de equipo de docentes presentan una propuesta metodológica de elaboración de rúbricas acerca de las competencias transversales en la Universidad de Barcelona. Cebrián, Serrano y Ruiz (2014) investigaron experimentalmente el impacto de las eRúbricas -rúbricas electrónicas- en la evaluación de los aprendizajes universitarios en sus diferentes modalidades y el alcance de esta herramienta para mejorar el aprendizaje de las competencias o habilidades cooperativas, producto del trabajo en equipo y la evaluación cooperativa de tareas en el laboratorio. Pérez-Pérez (2014) investigó el trabajo en equipo mediante el uso del portafolio y las rúbricas de evaluación, señala que los estudiantes "han sentido la asignatura y los trabajos a realizar realmente como suyos al ser partícipes de la misma; han controlado la materia en todo momento, reflejado en la autoevaluación que hicieron sobre su trabajo, en las exposiciones, reflexiones del portafolio, examen, etc." (p.72). Por su parte Etxabe, Aranguren y Losada (2011) desarrollaron rúbricas en la formación de maestros de educación especial y educación primaria de la Universidad del País Vasco, con el objetivo de coordinar y homogeneizar la evaluación de las competencias comunes de cinco asignaturas que comparten un grupo de alumnos/as; como resultado, a partir del curso 2007/2008 se constató una clara mejora en las calificaciones con el uso de este instrumento.

Sainz y Bol (2014) comprobaron que la metodología basada en la utilización de rúbricas que facilitan un feedback sobre el proceso de resolución de las tareas, no aporta diferencias significativas inmediatas, aunque sí parece proporcionar cambios en el proceso de autorregulación del aprendizaje y el desarrollo de aprendizajes más profundos; asimismo mejora la autopercepción del aprendizaje en los estudiantes (del grado de ingeniería civil). Torres y Perera (2010) proponen una rúbrica denominada RETAF como una herramienta para tutorizar y evaluar el trabajo en los foros online (o herramientas asincrónicas) en la formación universitaria, aplicable en cualquier área científica; organizado en cuatro categorías: aspectos formales, participación en el foro, análisis de las aportaciones y evidencias de aprendizaje. Rodriguez-Gallego (2014) desarrollaron una experiencia de elaboración de rúbricas consensuadas con los estudiantes para la mejora de su aprendizaje, con alumnos del grado de educación primaria, en la asignatura de Tecnologías de la Información y la Comunicación, de la Facultad de Ciencias de la Educación de la Universidad de Sevilla, diseñaron diferentes rúbricas analíticas para trece tareas prácticas y para evaluar el trabajo de investigación; los estudiantes manifestaron que han mejorado su aprendizaje al utilizar autónomamente para revisar sus trabajos y cuando su compañero los ha utilizado; a la vez consideran que es más justa.

Un avance en la validación de las rúbricas como instrumentos de evaluación presentan Marín, Guzmán y Castro (2012) en niños de preescolar, con la puesta en práctica de tres diferentes formas de aplicación del instrumento. Los resultados señalan niveles de fiabilidad altos y poder de discriminación que permite diferenciar significativamente sujetos por edad y nivel socioeconómico, no hallando diferencias por género. Valverde J. y Ciudad A. (2014) diseñaron dos rúbricas para su aplicación en la asignatura de «Estados de Información Empresarial» de Grado en Finanzas y contabilidad de la Universidad de Extremadura, con la participación de seis grupos de trabajo, quienes aplicaron la auto-evaluación y evaluación por pares, a través de actividades presenciales y on-line orientadas a la formación y evaluación de las compe- 
tencias y que han sido incluidas de manera organizada en la plataforma Moodle. Reporta una fiabilidad de o,877 en la fase A y o, 847 en la fase B según el Alpha de Cronbach, considerados aceptables. Guzmán, Flores y Tirado F. (2012) elaboraron y validaron rúbricas para evaluar la competencia argumentativa de los mensajes escritos en foros de discusión en línea, por trece jueces, se analizaron 93 mensajes y se obtuvo un alpha de Cronbach de 0.845 .

Como se puede evidenciar en la revisión de los antecedentes son escasos los estudios sobre la validación de las rúbricas como instrumentos de evaluación en la educación superior.

En este contexto se planteó el objetivo de determinar la validez y confiabilidad de las rúbricas utilizadas como instrumentos de evaluación en asignaturas desarrollados con los estudiantes de la Facultad de Educación de la Universidad Nacional de Centro del Perú, en las modalidades de autoevaluación, coevaluación y heteroevaluación.

La validez consiste en la exactitud y pertinencia en que un instrumento mide lo que se propone medir; es decir, si el instrumento contiene la cantidad y la calidad adecuada y suficiente de reactivos o indicadores para sostener que el instrumento mide la variable y sus dimensiones seleccionadas. Se tiene cuatro tipos de validez: validez predictiva, validez concurrente, validez de contenido y validez de constructo (APA, 2010).

La confiabilidad se refiere al grado de consistencia o concordancia de los resultados por los mismos sujetos cuando se les aplica el mismo instrumento en diferentes ocasiones. Se espera que un instrumento confiable debe arrojar resultados similares o iguales cuando no se ha producido cambios o modificaciones en la variable o dimensión que se está evaluando. Asimismo, cuando una prueba tiene como propósito evaluar un rasgo unitario, todos sus elementos deben presentar alta correlación entre ellos (inter items).

\section{Material y método}

El estudio fue descriptivo e interpretativo, en un primer momento, se utilizó la técnica de análisis documental y análisis de contenido de fuentes bibliográficas e investigaciones realizadas en este campo, para la elaboración de las rúbricas.

La estructura básica de las rúbricas contiene: los datos informativos, los criterios de desempeño, una escala valorativa progresiva (en cuatro niveles de desempeño: en inicio, en proceso, logro aceptable y logro destacado), los descriptores para cada nivel de desempeño, la ponderación de cada criterio, y el espacio para las sugerencias de mejora.

Basado en las experiencias de Alsina y otros (2013), Gatica-Lara F. y Uribarren-Berrueta T., (2013) y Tobón (2013) se adoptó el siguiente procedimiento de elaboración y uso de las rúbricas:

1ro. Presentación breve de los datos referenciales de la asignatura, módulo, proyecto o curso donde se aplicará el instrumento.

2do. Determinar la competencia/capacidad a ser trabajada con los estudiantes, sus procesos básicos y/o producto.

3ro. Determinar los criterios e indicadores relevantes de proceso o producto de acuerdo con la competencia o capacidad que se va a evaluar. 
4to. Asumir/adaptar un modelo de niveles de desempeño o dominio

5to. Elaborar los descriptores para cada uno de los niveles de dominio, considerando el indicador y criterio.

6to. Determinar el valor cuantitativo (ponderación) del indicador y distribuir en cada nivel de dominio.

7mo. Adecuar el formato y contenido de la rúbrica para la autoevaluación, coevaluación y heteroevaluación.

8 vo. Analizar la rúbrica con los estudiantes antes de realizar el trabajo, buscando la comprensión y el compromiso; puede negociarse algunos descriptores con ellos. Dejar claro que primero ellos realizaran su autoevaluación, luego la coevaluación de pares antes de pasar a la heteroevaluación por parte del profesor.

En un segundo momento, la investigación consistió en la aplicación del grupo de rúbricas para la evaluación de procesos y productos del aprendizaje con enfoque de competencias en estudiantes de educación superior universitaria, para su respectiva validación.

Participaron un total de 61 estudiantes de pregrado, de las carreras profesionales de Ciencias naturales y ambientales y de Ciencias matemáticas e informática, con quienes se aplicaron las rúbricas para evaluar monografía, ensayo y exposición discusión grupal. Las rúbricas para evaluar proyectos de tesis y artículo académico fueron aplicadas en 65 doctorandos de la Escuela de posgrado de la UNCP y de la UNSCH. Ambos grupos en el periodo académico 2017 y 2018.

Para evaluar la confiabilidad se aplicó el coeficiente de consistencia interna alfa de Cronbach. Este coeficiente toma valores entre o y 1, y un valor mayor a o,7 indica que el instrumento es confiable.

La validez de contenido de las rúbricas fue evaluada por siete académicos de la Facultad de Educación - UNCP, entre maestros y doctores. Para establecer la validez estadística de las rúbricas como instrumento de evaluación en estudiantes universitarios, se utilizó el coeficiente de correlación corregida $r$ de Pearson. Este coeficiente toma valores entre -1 y 1. Los ítems cuyas correlaciones ítem-total arrojen valores de 0,2 a más son válidos y deben ser conservados, mientras que los ítems con correlaciones inferiores a 0,2 son no válidos y deben ser reformulados o desechados. Por regla general, el instrumento de medición es válido si todos sus ítems son válidos.

\section{Resultados}

Se han elaborado, aplicado y validado un grupo de rúbricas de evaluación de productos con enfoque de competencias en diversas asignaturas desarrolladas en el periodo 2017-I al 2018-I, con estudiantes universitarios de pregrado y posgrado.

\section{En pre grado:}

a) Rúbricas para la valoración de la exposición-discusión de trabajos grupales (ver anexo).

b) Rúbricas para la valoración de monografías (ver anexo) 
c) Rúbricas para la valoración de ensayos académicos (ver anexo)

En pos grado:

d) Rúbricas para la valoración de proyectos de tesis (ver anexo)

e) Rúbricas para la valoración de artículos académicos (ver anexo)

\section{Evaluación de la validez}

En las Tablas que siguen se ilustran los coeficientes de correlación r de Pearson corregida ítem-total de las rúbricas (Correlación total de elementos corregida, cuarta columna).

Tabla 1.

Evaluación de la validez de la primera autoevaluación de la monografía

\begin{tabular}{lcccc}
\multicolumn{5}{c}{ Estadísticas de total de elemento } \\
\hline \hline & $\begin{array}{c}\text { Media de } \\
\text { escala si el } \\
\text { elemento se } \\
\text { ha suprimido }\end{array}$ & $\begin{array}{c}\text { Varianza de } \\
\text { escala si el } \\
\text { elemento se } \\
\text { ha suprimido }\end{array}$ & $\begin{array}{c}\text { Correlación } \\
\text { total de } \\
\text { elementos } \\
\text { corregida }\end{array}$ & $\begin{array}{c}\text { Alfa de } \\
\text { Cronbach si el } \\
\text { elemento se ha } \\
\text { suprimido }\end{array}$ \\
\hline $\begin{array}{l}\text { Presentación según } \\
\text { estructura A1 }\end{array}$ & 21,33 & 19,867 &,- 843 &, 455 \\
Formato adecuado A1 & 21,83 & 16,567 &, 032 &, 314 \\
Indice e introducción A1 & 20,50 & 23,100 &,- 866 &, 585 \\
Desarrollo de contenido A1 & 19,83 & 5,767 &, 776 &,- 597 \\
Claridad y coherencia A1 & 19,50 & 3,900 &, 753 &,- 841 \\
Conclusiones A1 & 20,33 & 13,867 &, 291 &, 202 \\
Referencias bibliográficas A1 & 21,67 & 14,267 &, 316 &, 207 \\
\hline \hline
\end{tabular}

Tabla 2.

Evaluación de la validez de la heteroevaluación de la monografía

Estadísticas de total de elemento

\begin{tabular}{lcccc}
\hline \hline & $\begin{array}{c}\text { Media de } \\
\text { escala si el } \\
\text { elemento se } \\
\text { ha suprimido }\end{array}$ & $\begin{array}{c}\text { Varianza de } \\
\text { escala si el } \\
\text { elemento se } \\
\text { ha suprimido }\end{array}$ & $\begin{array}{c}\text { Correlación } \\
\text { total de } \\
\text { elementos } \\
\text { corregida }\end{array}$ & $\begin{array}{c}\text { Alfa de } \\
\text { Cronbach si el } \\
\text { elemento se } \\
\text { ha suprimido }\end{array}$ \\
\hline $\begin{array}{l}\text { Presentación según } \\
\text { estructura H }\end{array}$ & 24,83 & 9,767 &, 909 &, 541 \\
Formato adecuado H & 25,17 & 9,767 &, 708 &, 557 \\
Indice e introducción H & 24,50 & 7,100 &, 449 &, 631 \\
Desarrollo de contenido H & 22,50 & 11,100 &, 221 &, 663 \\
Claridad y coherencia H & 22,50 & 12,700 &,- 069 &, 731 \\
Conclusiones H & 24,33 & 10,267 &, 275 &, 655 \\
Referencias bibliográficas H & 25,17 & 9,767 &, 708 &, 557 \\
\hline \hline
\end{tabular}

La rúbrica para la valoración de la monografía es válida en seis criterios de siete según resultados de la autoevaluación, pues los coeficientes de la correlación total de elementos corregida (cuarta columna de tabla 3) son mayores que 0,2. De manera similar, según resultados de la heteroevaluación seis de los siete criterios son válidos. Los ítems/criterios no válidos 
corresponden al $\mathrm{C}_{2}$ formato y al $\mathrm{C}_{5}$ claridad y coherencia, luego, estos criterios han sido corregidos. Por lo que la rúbrica para valoración de la monografía presenta validez de constructo (validez objetiva o de campo).

Para la validación de las rúbricas para evaluar las exposiciones y discusiones grupales, tambien se ha utilizado la técnica de correlación corregida $r$ de Pearson, cuyos resultados se presentan en las tablas 5, 6 y 7 a través de cuatro grupos.

Tabla 3.

Validez de la rúbrica para valorar la exposición-discusión grupal 1

Estadísticas de total de elemento

\begin{tabular}{|c|c|c|c|c|}
\hline Criterios & $\begin{array}{c}\text { Media de } \\
\text { escala si el } \\
\text { elemento se } \\
\text { ha suprimido }\end{array}$ & $\begin{array}{c}\text { Varianza de } \\
\text { escala si el } \\
\text { elemento se } \\
\text { ha suprimido }\end{array}$ & $\begin{array}{l}\text { Correlación } \\
\text { total de } \\
\text { elementos } \\
\text { corregida }\end{array}$ & $\begin{array}{c}\text { Alfa de } \\
\text { Cronbach si el } \\
\text { elemento se } \\
\text { ha suprimido }\end{array}$ \\
\hline $\begin{array}{l}\text { Organización y } \\
\text { colaboración G2 }\end{array}$ & 11,00 & 2,545 & 463 &, 429 \\
\hline Material de exposición G2 & 10,67 & 1,697 &, 598 &, 214 \\
\hline Dominio del tema G2 & 10,67 & 1,697 &, 598 &, 214 \\
\hline $\begin{array}{l}\text { Capacidad reflexiva y } \\
\text { critica } G 2\end{array}$ & 10,67 & 3,152 &,- 088 & ,808 \\
\hline
\end{tabular}

Tabla 4.

Validez de la rúbrica para valorar la exposición-discusión grupal 2

Estadísticas de total de elemento

\begin{tabular}{lcccc}
\hline \hline & $\begin{array}{c}\text { Media de } \\
\text { escala si el } \\
\text { elemento se } \\
\text { ha suprimido }\end{array}$ & $\begin{array}{c}\text { Varianza de } \\
\text { escala si el } \\
\text { elemento se } \\
\text { ha suprimido }\end{array}$ & $\begin{array}{c}\text { Correlación } \\
\text { total de } \\
\text { elementos } \\
\text { corregida }\end{array}$ & $\begin{array}{c}\text { Alfa de } \\
\text { Cronbach si el } \\
\text { elemento se } \\
\text { ha suprimido }\end{array}$ \\
\hline $\begin{array}{l}\text { Organización y } \\
\text { colaboración G3 }\end{array}$ & 9,50 & 5,000 &, 731 &, 727 \\
$\begin{array}{l}\text { Material de exposición G3 } \\
\begin{array}{l}\text { Dominio del tema G3 } \\
\text { Capacidad reflexiva y } \\
\text { crítica G3 }\end{array}\end{array}$ & 9,67 & 7,879 &, 388 &, 865 \\
\hline \hline
\end{tabular}

Tabla 5. Validez de la rúbrica para valorar la exposición-discusión grupal3

Estadísticas de total de elemento

\begin{tabular}{lcccc}
\hline \hline & $\begin{array}{c}\text { Media de } \\
\text { escala si el } \\
\text { elemento se } \\
\text { ha suprimido }\end{array}$ & $\begin{array}{c}\text { Varianza de } \\
\text { escala si el } \\
\text { elemento se } \\
\text { ha suprimido }\end{array}$ & $\begin{array}{c}\text { Correlación } \\
\text { total de } \\
\text { elementos } \\
\text { corregida }\end{array}$ & $\begin{array}{c}\text { Alfa de } \\
\text { Cronbach si el } \\
\text { elemento se ha } \\
\text { suprimido }\end{array}$ \\
\hline $\begin{array}{l}\text { Organización y } \\
\text { colaboración G4 }\end{array}$ & 10,00 & 9,818 &, 894 &, 333 \\
Material de exposición G4 & 9,67 & 9,697 &, 316 &, 563 \\
$\begin{array}{l}\text { Dominio del tema G4 } \\
\begin{array}{l}\text { Capacidad reflexiva y } \\
\text { crítica G4 }\end{array}\end{array}$ & 8,67 & 7,515 &, 254 &, 726 \\
\hline \hline
\end{tabular}


Tabla 6.

Validez de la rúbrica para valorar la exposición-discusión grupal 4

Estadísticas de total de elemento

\begin{tabular}{lcccc}
\hline \hline & $\begin{array}{c}\text { Media de } \\
\text { escala si el } \\
\text { elemento se } \\
\text { ha suprimido }\end{array}$ & $\begin{array}{c}\text { Varianza de } \\
\text { escala si el } \\
\text { elemento se } \\
\text { ha suprimido }\end{array}$ & $\begin{array}{c}\text { Correlación } \\
\text { total de } \\
\text { elementos } \\
\text { corregida }\end{array}$ & $\begin{array}{c}\text { Alfa de } \\
\text { Cronbach si el } \\
\text { elemento se } \\
\text { ha suprimido }\end{array}$ \\
\hline $\begin{array}{l}\text { Organización y } \\
\text { colaboración G5 }\end{array}$ & 9,67 & 15,152 &, 978 &, 858 \\
$\begin{array}{l}\text { Material de exposición G5 } \\
\begin{array}{l}\text { Dominio del tema G5 } \\
\text { Capacidad reflexiva y } \\
\text { crítica G5 }\end{array}\end{array}$ & 10,00 & 14,182 &, 952 &, 853 \\
\hline \hline
\end{tabular}

De acuerdo con los resultados, la rúbrica para la valoración de la exposición - discusión grupal es válida, pues los coeficientes de la correlación total de elementos corregida (cuarta columna de las tablas) son mayores que o,2; por lo que este instrumento presenta validez de constructo (validez objetiva o de campo).

Para el nivel de posgrado se han elaborado y validado dos rúbricas: la rúbrica para evaluación de proyectos de tesis y la rúbrica para la evaluación de artículos académicos.

Tabla 7.

Evaluación de la validez de la rúbrica de autoevaluación del proyecto de tesis

\begin{tabular}{|c|c|c|c|c|}
\hline \multicolumn{5}{|c|}{ Estadísticas de total de elemento } \\
\hline Criterios & $\begin{array}{c}\text { Media de } \\
\text { escala si el } \\
\text { elemento se } \\
\text { ha suprimido } \\
\end{array}$ & $\begin{array}{c}\text { Varianza de } \\
\text { escala si el } \\
\text { elemento se } \\
\text { ha suprimido }\end{array}$ & $\begin{array}{c}\text { Correlación } \\
\text { total de } \\
\text { elementos } \\
\text { corregida } \\
\end{array}$ & $\begin{array}{c}\text { Alfa de } \\
\text { Cronbach si el } \\
\text { elemento se } \\
\text { ha suprimido }\end{array}$ \\
\hline Título A & 49,00 & 39,478 &, 000 &, 574 \\
\hline $\begin{array}{l}\text { Desarrollo de la estructura } \\
\text { básica del proyecto A }\end{array}$ & 48,67 & 40,058 &,- 084 &, 583 \\
\hline $\begin{array}{l}\text { Planteamiento del } \\
\text { problema A }\end{array}$ & 48,46 & 40,694 &,- 171 &, 591 \\
\hline Análisis de antecedentes A & 47,21 & 32,607 &, 309 &, 524 \\
\hline $\begin{array}{l}\text { Bases teóricas y } \\
\text { definiciones conceptuales A }\end{array}$ & 46,79 & 35,563 & 243 &, 542 \\
\hline Hipótesis A & 47,83 & 33,971 & 221 &, 547 \\
\hline Metodología A & 49,29 & 34,303 & .453 &, 511 \\
\hline $\begin{array}{l}\text { Administrativa y } \\
\text { presupuestal A }\end{array}$ & 48,96 & 31,955 &, 567 & 478 \\
\hline Referencias bibliográficas $\mathrm{A}$ & 46,88 & 37,766 &,- 096 &, 673 \\
\hline Matriz de consistencia A & 48,29 & 33,694 &, 425 &, 508 \\
\hline Relevancia y aportes A & 45,75 & 24,717 &, 508 & .444 \\
\hline Originalidad A & 48,08 & 32,167 & 568 & 480 \\
\hline
\end{tabular}

La rúbrica para la evaluación del proyecto de tesis, en cuatro de los once criterios tienen valores menores a 0.2, por lo que éstas no serían válidas. Sin embargo, los once criterios restantes tienen valores mayores a o.2, por lo que éstas son válidas. 
En cuanto al artículo académico, se aplicó y validó con estudiantes del I semestre de maestría, cuyos resultados se presentan en la tabla siguiente.

Tabla 8.

Evaluación de la validez de la autoevaluación del artículo académico

\begin{tabular}{|c|c|c|c|c|}
\hline \multicolumn{5}{|c|}{ Estadísticas de total de elemento } \\
\hline Criterios & $\begin{array}{l}\text { Media de } \\
\text { escala si el } \\
\text { elemento se } \\
\text { ha suprimido }\end{array}$ & $\begin{array}{l}\text { Varianza de } \\
\text { escala si el } \\
\text { elemento se } \\
\text { ha suprimido }\end{array}$ & $\begin{array}{l}\text { Correlación } \\
\text { total de } \\
\text { elementos } \\
\text { corregida }\end{array}$ & $\begin{array}{c}\text { Alfa de } \\
\text { Cronbach si el } \\
\text { elemento se ha } \\
\text { suprimido }\end{array}$ \\
\hline Título sintético A & 24,68 & 16,799 & 079 & 754 \\
\hline $\begin{array}{l}\text { Desarrolla la estructura } \\
\text { básica } \mathrm{A}\end{array}$ & 24,95 & 14,998 &, 268 &, 735 \\
\hline $\begin{array}{l}\text { Contenido del resumen y } \\
\text { abstract } A\end{array}$ & 24,73 & 13,827 &, 636 &, 677 \\
\hline $\begin{array}{l}\text { Introducción presenta las } \\
\text { bases teóricas, epistémicas } \\
\text { y antecedentes articuladas A }\end{array}$ & 23,55 & 7,593 & ,853 &, 562 \\
\hline $\begin{array}{l}\text { Planteamiento de tesis y } \\
\text { argumentos A }\end{array}$ & 23,55 & 7,593 & 853 &, 562 \\
\hline Discusión y/o conclusiones A & 24,50 & 16,262 &, 249 &, 738 \\
\hline $\begin{array}{l}\text { Referencias bibliográficas } \\
\text { completas } \mathrm{A}\end{array}$ & 24,50 & 15,881 &, 364 &, 727 \\
\hline
\end{tabular}

Tabla 9.

\section{Evaluación de la validez de la coevaluación del artículo académico}

\section{Estadísticas de total de elemento}

\begin{tabular}{lcccc}
\hline \hline & $\begin{array}{c}\text { Media de } \\
\text { escala si el } \\
\text { elemento se } \\
\text { ha suprimido }\end{array}$ & $\begin{array}{c}\text { Varianza de } \\
\text { escala si el } \\
\text { elemento se } \\
\text { ha suprimido }\end{array}$ & $\begin{array}{c}\text { Correlación } \\
\text { total de } \\
\text { elementos } \\
\text { corregida }\end{array}$ & $\begin{array}{c}\text { Alfa de } \\
\text { Cronbach si el } \\
\text { elemento se ha } \\
\text { suprimido }\end{array}$ \\
\hline $\begin{array}{l}\text { Titulo sintético C } \\
\begin{array}{l}\text { Desarrolla la estructura } \\
\text { básica C }\end{array}\end{array}$ & 25,91 & 12,810 &, 378 &, 675 \\
$\begin{array}{l}\text { Contenido del resumen y } \\
\text { abstract C } \\
\text { Introducción presenta las } \\
\text { bases teóricas, epistémicas y } \\
\text { antecedentes articuladas C }\end{array}$ & 26,00 & 12,273 &, 496 &, 657 \\
$\begin{array}{l}\text { Planteamiento de tesis y } \\
\text { argumentos C }\end{array}$ & 24,52 & 12,447 &, 506 &, 509 \\
$\begin{array}{l}\text { Discusión y/o conclusiones C } \\
\text { Referencias bibliográficas } \\
\text { completas C }\end{array}$ & 24,52 & 5,988 &, 777 &, 488 \\
\hline \hline
\end{tabular}

De acuerdo con los resultados de la autoevaluación, seis criterios de siete arrojan resultados mayores a 0.2 por lo que estos son válidos, sin embargo, el criterio referido a "título sintético" presenta valores menores que o,2, por lo que ésta no sería válida, merece la corrección respectiva. 


\section{Evaluación de la confiabilidad}

En cuanto a la confiabilidad de la rúbrica para evaluar monografía, de acuerdo con los resultados del Alfa de Cronbach, en la primera autoevaluación se tienen 0,307 confiabilidad muy baja, en cambio en la segunda autoevaluación se tiene o, 660 lo que corresponde a una confiabilidad moderada, pero no llega al nivel ideal (> 0.70).

La rúbrica para evaluar exposiciones- discusiones grupales son confiables según los resultados de tres grupos: 0,$817 ; 0,590$ y o,919, sobre todo en el primer y tercer grupo con los que se alcanza a una confiabilidad alta. La rúbrica para la evaluación del ensayo académico resulta confiable en los procesos de coevaluación y heteroevaluación, por cuanto se tiene un Alfa de Cronbach de o,819 y 0.877 . Sin embargo, según los resultados de la autoevaluación resulta no confiable (0.433).

La rúbrica para la evaluación de proyecto de tesis resulta moderadamente confiable, por cuanto se tiene un Alfa de Cronbach de 0,565 . Y finalmente, en cuanto a la rúbrica para evaluar el artículo académico también resulta confiable en el proceso de autoevaluación y moderadamente confiable en la coevaluación.

\section{Discusión}

Las rúbricas son instrumentos de evaluación cualitativos que definen descriptores de desempeños en niveles de avance o logro que va de lo simple a lo complejo en base a criterios cuya principal finalidad es compartir los criterios de realización de las tareas o productos entre los profesores y los estudiantes (Alsina y otros, 2013; Ávila y otros, 2015).

En esta investigación, se ha adaptado una estructura básica de las rúbricas que contiene por cada producto o proceso a evaluar, los criterios de desempeño, una escala valorativa progresiva que contiene los descriptores para cada nivel y una ponderación por criterio. En estas rúbricas se ha elegido y utilizado la siguiente escala valorativa: en inicio, en proceso, logro aceptable y logro destacado por ser de fácil comprensión y manejo para los estudiantes, sin embargo, existen otras propuestas como el de Tobón (2013) con cinco niveles: preformal, receptivo, resolutivo, autónomo y estratégico para la valoración de competencias.

Con estudiantes de diversos semestres de pre y posgrado de la Facultad de Educación se ha elaborado y aplicado cinco rúbricas. En todos los casos se presentó y se analizó los criterios y niveles de valoración de los procesos y productos a evaluar con los estudiantes, asimismo se estableció como regla general que primero se realiza la autoevaluación de sus trabajos o procesos, luego la coevaluación por parte de sus compañeros y finalmente el profesor aplica la heteroevaluación; para ello se ha adaptado las rúbricas para estas tres formas de evaluación. Dando lugar a una evaluación participativa, volviendo el rol activo a los mismos estudiantes.

Como resultado se ha elaborado y aplicado cinco rúbricas de evaluación de productos con enfoque de competencias en diversas asignaturas desarrolladas en el periodo 2017-I al 2018-I, con un total de 106 estudiantes universitarios de pregrado y posgrado de la Facultad de Educación.

En el pregrado, las rúbricas elaboradas, aplicadas y validadas son las siguientes: 
$\checkmark$ Rúbricas para la valoración de la exposición-discusión de trabajos grupales: propuesta para autoevaluación, coevaluación y heteroevaluación. (ver anexo)

$\checkmark$ Rúbricas para la valoración de monografías: propuesta para autoevaluación, coevaluación y heteroevaluación. (ver anexo)

$\checkmark$ Rúbricas para la valoración de ensayos académicos: propuesta para la autoevaluación, coevaluación y heteroevaluación. (ver anexo)

En posgrado se tiene las siguientes rúbricas:

$\checkmark$ Rúbricas para la valoración de proyectos de tesis: propuesta para autoevaluación, coevaluación y heteroevaluación. (ver anexo)

$\checkmark$ Rúbricas para la valoración de artículos académicos: propuesta para autoevaluación, coevaluación y heteroevaluación. (ver anexo)

La validez de las rúbricas comprende la validez de contenido (validez teórica, de escritorio o subjetiva) y la validez de constructo (validez práctica, de campo u objetiva). La primera se evalúa con la opinión de expertos y el coeficiente de concordancia $V$ de Aiken para cada uno de los criterios (validez genérica) e ítems (validez específica) de las rúbricas, y la segunda con los resultados de su aplicación a muestras pilotos de estudiantes de pregrado y posgrado de la UNCP, y el coeficiente de correlación corregida r de Pearson ítem-total. La confiabilidad de las rúbricas se evalúa con los resultados de su aplicación a muestras pilotos de estudiantes de pregrado y posgrado de la UNCP, y el coeficiente de consistencia interna alfa de Cronbach.

Según la técnica de jueces, se tiene que la rúbrica para valorar la monografía presenta validez de contenido genérica en los siete criterios generales como claridad, objetividad, organización, suficiencia, coherencia, pertinencia y ponderación; de modo similar y tienen validez de contenido específica en los siete criterios de desempeño como son: la presentación según estructura, uso de formato, organización del índice e introducción, desarrollo del contenido, claridad y coherencia, conclusiones y referencias bibliográficas, los que han sido calificadas como alta, excelente y perfecta. En tanto que la rúbrica para evaluar exposiciones y discusiones grupales tiene validez de contenido general y especifica; con excepción al criterio de claridad que resultó no válido. La rúbrica para la valoración de ensayos académicos resultó válida en los siete criterios genéricos y en los cinco criterios específicos resulta entre excelente y perfecta.

En el nivel de posgrado, la rúbrica para evaluar proyectos de tesis resulta válida en los siete criterios genéricos y en los doce criterios específicos: título, desarrollo de la estructura, planteamiento del problema, análisis de antecedentes, bases teóricas, hipótesis, metodología, referencia bibliográfica, originalidad e innovación, pertinencia, relevancia y aportes y, claridad y coherencia calificados como excelente y perfecta. En cuanto a la rúbrica para evaluar artículos académicos resulta válida en los siete criterios genéricos y en los siete criterios específicos como el título, desarrollo de la estructura básica, presentación de resumen y abstract, introducción, planteamiento de tesis y argumentos, discusión/conclusiones y referencias bibliográficas, calificadas con validez perfecta.

En cuanto a la validez de constructo, de acuerdo con los resultados de los grupos pilotos en los que se aplicaron las rúbricas, los datos de validez difieren levemente según las modalidades de aplicación, ya sea en autoevaluación, coevaluación o heteroevaluación. En la rúbrica para la valoración de la monografía es válida en seis criterios de siete según resultados de la autoevaluación y heteroevaluación. Los ítems/criterios no válidos corresponden al $C_{2}$ formato 
y al $C_{5}$ claridad y coherencia, por lo que estos criterios han sido corregidos. La rúbrica para la valoración de la exposición - discusión grupal es válida, pues los coeficientes de la correlación total de elementos corregida son mayores a o.2. Según los resultados de la coevaluación y heteroevaluación, la rúbrica para valorar el ensayo académico es válida, sin embargo, de acuerdo con los resultados de la autoevaluación uno de los criterios no es válida.

A nivel de posgrado, la rúbrica para la evaluación del proyecto de tesis, en cuatro de los once criterios no es válida, sin embargo, los siete criterios restantes tienen valores mayores a o.2, por lo que éstas son válidas. Entonces el instrumento en general no sería válido estadísticamente. De acuerdo con los resultados de la autovaloración de la rúbrica para evaluar artículos académicos, seis criterios de siete arrojan resultados mayores a 0.2 por lo que estos son válidos, sin embargo, el criterio referido a "título sintético" presenta valores menores que o,2, por lo que ésta no sería válida, merece la corrección respectiva.

Los resultados de la confiabilidad también son relativamente diferenciados según la modalidad de aplicación, sea la autoevaluación, coevaluación y heteroevaluación. En la rúbrica para evaluar monografía, de acuerdo con los resultados del Alfa de Cronbach, en la primera autoevaluación se tiene o,307 confiabilidad muy baja, en cambio, en la segunda autoevaluación se tiene o, 660 lo que corresponde a una confiabilidad moderada, pero no llega al nivel ideal (> 0.70). La rúbrica para evaluar exposiciones- discusiones grupales son confiables según los resultados de tres grupos de coevaluación: o,817; 0,590 y o,919, sobre todo en el primer y tercer grupo con los que se alcanza a una confiabilidad alta. La rúbrica para la evaluación del ensayo académico, resulta confiable en los procesos de coevaluación y heteroevaluación, por cuanto se tiene un Alfa de Cronbach de o,819 y 0.877. Sin embargo, según los resultados de la autoevaluación resulta no confiable (0.433).

En el nivel de posgrado, la rúbrica para la evaluación de proyecto de tesis, resulta moderadamente confiable, por cuanto se tiene un Alfa de Cronbach de o,565. Y finalmente, en cuanto a la rúbrica para evaluar el artículo académico también resulta confiable en el proceso de autoevaluación y moderadamente confiable en la coevaluación.

En un análisis cualitativo, como puede observarse en cada una de las rúbricas, éstas muestran esencialmente descripciones cualitativas, especificaciones de diferentes niveles de logro o avance en cada criterio de evaluación o indicador de desempeño; lo cual constituye una gran ventaja para el estudiante, sobre todo en la autoevaluación, porque ellos mismos pueden verificar su trabajo o contrastar su exposición y ubicarse en algún nivel de desempeño entonces buscan avanzar más, o hacerlo cada vez mejor, porque ningún alumno o grupo se atreve a presentar su trabajo con una valoración baja, entonces vuelven a hacer, se autoevalúan nuevamente y si consideran que ya está mejor, recién presentan su trabajo, pues concordando con Alsina (2013) permite al estudiante monitorizar la propia actividad, autoevaluándose y favoreciendo la responsabilidad ante los aprendizajes. Ahora en la coevaluación también resulta muy interesante el diálogo y discusión establecido entre los grupos o estudiantes, porque tratan de evidenciar sus fortalezas y debilidades, pero sobre todo se corrigen y mejoran y ambos aprenden mucho más, el que sabe enseña y el que no sabe aprende con las rúbricas y con la técnica de coevaluación; lo que en verdad está ocurriendo es que los estudiantes y grupos de estudiantes están empezando o avanzando en sus capacidades y habilidades de autorregulación y autonomía, lo que pedagógicamente es muy significativo.

Hay avances significativos mostrados en la autoevaluación y la coevaluación, en tanto la heteroevaluación aplicado por el docente es mucho más sencillo, pero sobre todo es satisfac- 
torio, porque el maestro lo que hace es verificar qué tan bien y coherentes (o responsables) son en su autoevaluación o coevaluación de sus trabajos en cada uno de los indicadores o criterios de evaluación. Generalmente se llega a una verificación satisfactoria, ningún alumno o grupo se desaprueba, todos apuntan a llegar al logro destacado.

Una de las limitaciones en la presente investigación acerca de las rúbricas es que éstas fueron elaboradas por el docente en su mayoría. Entonces, es de esperar que sería mucho más ventajoso, si los mismos estudiantes elaboran las rúbricas según los criterios de evaluación que puede proporcionar el docente, o en todo caso, tanto el docente como los estudiantes acuerdan y precisan los descriptores de los niveles de logro.

Por otro lado, coincidimos con Alsina y otros (2013) que el resultado del análisis, de las definiciones, de los indicadores y de las propias rúbricas no es generalizable, pero constituye un material de primera mano para el desarrollo e implementación de las rúbricas en la evaluación de las asignaturas a partir de los modelos ofrecidos. Sin embargo, algunas de las rúbricas como el de evaluación de proyectos o artículos de investigación pueden ser aplicadas en diversas asignaturas, incluso en semestres superiores y posgrado.

Finalmente, concordamos plenamente con Rodriguez-Gallego (2014) cuando señala que los datos recabados en esta investigación van a permitir consolidar nuestras rúbricas, en próximos estudios, para la búsqueda de cotas significativas de validez y fiabilidad en otros contextos y áreas curriculares.

\section{Conclusiones}

Las rúbricas para la evaluación de monografías presentan validez de contenido y de constructo, y confiabilidad moderada en la segunda autoevaluación, en estudiantes de pregrado.

Las rúbricas para la evaluación de exposiciones - discusiones grupales tienen validez de contenido, de constructo y son confiables en estudiantes de pregrado.

Las rúbricas para la evaluación de ensayos académicos tienen validez de contenido, de constructo y son confiables en estudiantes de pregrado.

Las rúbricas para la evaluación de proyectos de tesis de posgrado son válidas (de contenido y constructo) y son confiables en estudiantes de posgrado.

Las rúbricas para la evaluación de artículos académicos tienen validez de contenido y de constructo, y confiables en estudiantes de posgrado. 
Alsina J. y otros (2013). Rúbricas para la evaluación de competencias. Barcelona: ICE y Ediciones Octaedro.

APA (2010) Manual de publicaciones de la American Psychological Association. México: Manual Moderno.

Ávila N. y otros (2015) Rúbricas y otras herramientas para desarrollar la escritura en el aula. Chile: Santillana del Pacífico.

Blanco A. (2011) Tendencias actuales de la investigación educativa sobre las rúbricas. En: Bujan K., Rekalde I. y Aramendi P. (2011). La evaluación de competencias en la educación superior. Las rúbricas como instrumento de evaluación. Colombia: Eduforma-Ediciones de la U, pp.59-74.

Cano M.A. (2008) La evaluación por competencias en la educación superior. Revista de Currículum y Formación de Profesorado, Vol. 12, Núm. 3, 2008, pp. 1-16. España: Universidad de Granada

Cebrian M., Serrano J y Ruiz M. (2014) Las eRúbricas en la evaluación cooperativa del aprendizaje en la Universidad. Revista científica de educamunicación, Nro. 43, Vol. XXII, pp 153-161. España.

Champin, D. (2014). Evaluación por competencias en la educación médica. Rev Peru Med Exp Salud Publica 14;31(3):566-71.

Etxabe J.M., Aranguren K.y Losada D. (2011). Diseño de rúbricas en la formación inicial de maestros/ as. Revista de Formación e Innovación Educativa Universitaria. Vol. 4, № 3, 156-169.

Fraile J., Pardo R. Panadero E. (2016). ¿Cómo emplear las rúbricas para implementar una verdadera evaluación formativa?. Revista Complutense de Educación, 28(4) 2017: 1321-1334

García-Sanz, M.P. (2014) La evaluación de competencias en educación superior mediante rúbricas: un caso práctico. Revista Electrónica Interuniversitaria de Formación del Profesorado, 17 (1), 87---106. DOI: http://dx.doi.org/10.6018/reifop.17.1. 198861.

Gatica-Lara F. y Uribarren-Berrueta T. (2013). ¿Cómo elaborar una rúbrica?. Inv Ed Med 2013;2(1):61-65.

Guzmán, Y.I. Flores R. y Tirado F. (2012). La evaluación de la competencia argumentativa en foros de discusión en línea a través de rúbricas. Innovación Educativa, vol. 12, número 60.

Hernández-Mosqueda, J.S., Tobón-Tobón, S. y Guerrero-Rosas, G. (2016). Hacia una evaluación integral del desempeño: las rúbricas socioformativas. Ra Ximhai 12(6): 359-376.

Marín, R., Guzmán, I. y Castro, G. (2012). Diseño y validación de un instrumento para la evaluación de competencias en preescolar. Revista Electrónica de Investigación Educativa, 14(1), 182202. Consultado en http://redie.uabc.mx/voli4no1/contenido-maringuzmanc.html.

Pérez-Pérez, I. (2014). El trabajo en equipo mediante el uso del portafolio y las rúbricas de evaluación: innovación en la enseñanza universitaria. REIRE, Revista d'Innovació i Recerca en Educació, 7 (1), 56-75.

Rodríguez-Gallego M. (2014) Evidenciar competencias con rúbricas de evaluación. Revista Escuela Abierta, (17) pp. 117-134, recuperado de http://www.ceuandalucia.es/escuelaabierta/pdf/ articulos_ea17/9-rodriguez17.pdf.

Sainz M.C. y Bol A. (2014) Aprendizaje basado en la evaluación mediante rúbricas en educación superior. SUMA PSICOL, 21(1):28-35.

Tobón S. (2013) Formación integral y competencias. Pensamiento complejo, currículo, didáctica y evaluación. Colombia: ECO Ediciones.

Torres, J. J. y Perera, V. H. (2010). La rúbrica como instrumento pedagógico para la tutorización y evaluación de los aprendizajes en el foro online en educación superior. Pixel-Bit. Revista de Medios y Educación, № 36 Enero 2010 pp.141 - 149.

Valverde J. y Ciudad A. (2014). El uso de e-rúbricas para la evaluación de competencias en estudiantes universitarios. Estudio sobre fiabilidad del instrumento. Revista de docencia universitaria REDU, Vol. 12 (1), Abril 2014, 49-79.

Villa, A. y Poblete, A. (2007) Aprendizaje basado en competencias.Una propuesta para la evaluación de las competencias genéricas. España: Universidad de Deusto-Ediciones Mensajero. 


\section{Anexo A: RÚBRICA PARA LA VALORACIÓN DE MONOGRAFÍAS}

Institución: Facultad de Educación - UNCP

Escuela profesional:

Asignatura:

Semestre:

Docente:

Fecha:

Producto a evaluar : : Monografías acerca de un tema:

\begin{tabular}{|c|c|c|c|c|}
\hline Criterios & En inicio & En avance & Logro aceptable & Logro destacado \\
\hline $\begin{array}{l}\text { C1: Presentación } \\
\text { según estructura } \\
\text { establecida. }\end{array}$ & $\begin{array}{l}\text { El trabajo contiene: } \\
\text { carátula, desarrollo } \\
\text { temático y bibliogra- } \\
\text { fía. }\end{array}$ & $\begin{array}{l}\text { El trabajo contiene: } \\
\text { carátula, índice, de- } \\
\text { sarrollo temático y } \\
\text { referencias biblio- } \\
\text { gráficas. }\end{array}$ & $\begin{array}{l}\text { El trabajo está orde- } \\
\text { nado y contiene: tí- } \\
\text { tulo, carátula, índice, } \\
\text { introducción, desa- } \\
\text { rrollo temático, con- } \\
\text { clusiones y referen- } \\
\text { cias bibliográficas. }\end{array}$ & $\begin{array}{l}\text { El trabajo está ordenado y } \\
\text { contiene: título sintético, ca- } \\
\text { rátula, índice, introducción, } \\
\text { desarrollo temático, conclu- } \\
\text { siones, referencias bibliográ- } \\
\text { ficas y anexos; con márgenes } \\
\text { y formato adecuado, incluye } \\
\text { figuras diversas. }\end{array}$ \\
\hline Ponderación & 1 & 2 & 3 & 4 \\
\hline $\begin{array}{l}\text { C2: Uso de for- } \\
\text { mato }\end{array}$ & $\begin{array}{l}\text { Manejo inadecuado } \\
\text { del formato: márge- } \\
\text { nes, interlineado, san- } \\
\text { gría, títulos. }\end{array}$ & \begin{tabular}{|l|} 
Algunos aspectos de \\
formato: márgenes, \\
interlineado, sangría, \\
títulos, subtítulos \\
y numeración son \\
aceptables
\end{tabular} & $\begin{array}{l}\text { Tiene manejo acep- } \\
\text { table del formato: } \\
\text { márgenes, interli- } \\
\text { neado, sangría, títu- } \\
\text { los, subtítulos y nu- } \\
\text { meración de página. } \\
\end{array}$ & $\begin{array}{l}\text { Tiene manejo óptimo del } \\
\text { formato: márgenes, inter- } \\
\text { lineado, sangría, títulos, } \\
\text { subtítulos y numeración de } \\
\text { página, aplicando normas de } \\
\text { redacción académica. }\end{array}$ \\
\hline Ponderación & 1 & 2 & 3 & 4 \\
\hline $\begin{array}{l}\text { C3: Presentación } \\
\text { del índice e in- } \\
\text { troducción }\end{array}$ & $\begin{array}{l}\text { Presenta algunos as- } \\
\text { pectos del índice e } \\
\text { introducción. }\end{array}$ & $\begin{array}{l}\text { Presenta algunos as- } \\
\text { pectos del índice e } \\
\text { introducción en for- } \\
\text { ma adecuada, pero } \\
\text { no está completa. }\end{array}$ & $\begin{array}{l}\text { Presenta la forma y } \\
\text { contenido del índice } \\
\text { e introducción en } \\
\text { forma adecuada y } \\
\text { completa. }\end{array}$ & $\begin{array}{l}\text { Presenta todos los aspectos } \\
\text { del índice e introducción en } \\
\text { forma adecuada y completa. }\end{array}$ \\
\hline Ponderación & 1 & 2 & 4 & 6 \\
\hline $\begin{array}{l}\text { C4: Desarrollo } \\
\text { del contenido }\end{array}$ & $\begin{array}{l}\text { En la redacción del } \\
\text { contenido no presen- } \\
\text { ta citas ni referencias } \\
\text { de autores }\end{array}$ & $\begin{array}{l}\text { En la redacción del } \\
\text { contenido presenta } \\
\text { pocas citas directas } \\
\text { o indirectas y sin co- } \\
\text { mentarios. }\end{array}$ & $\begin{array}{l}\text { El desarrollo del con- } \\
\text { tenido aplica citas } \\
\text { directas e indirectas, } \\
\text { con comentarios y } \\
\text { referencias de auto- } \\
\text { res. } \\
\end{array}$ & $\begin{array}{l}\text { En el desarrollo del conteni- } \\
\text { do aplica las normas de re- } \\
\text { dacción APA, con citas direc- } \\
\text { tas e indirectas relevantes, } \\
\text { con comentarios y referen- } \\
\text { cias de los autores citados. }\end{array}$ \\
\hline Ponderación & 1 & 4 & 6 & 8 \\
\hline $\begin{array}{l}\text { C5: Claridad y } \\
\text { coherencia }\end{array}$ & $\begin{array}{l}\text { No se percibe clari- } \\
\text { dad, no hay secuencia } \\
\text { adecuada de ideas al } \\
\text { desarrollar los temas. }\end{array}$ & $\begin{array}{l}\text { Se evidencia cierta } \\
\text { claridad, poca cohe- } \\
\text { rencia y secuencia de } \\
\text { ideas al desarrollar } \\
\text { los temas. }\end{array}$ & $\begin{array}{l}\text { Se evidencia clari- } \\
\text { dad, coherencia y se- } \\
\text { cuencia de ideas en } \\
\text { el tema general y en } \\
\text { cada subtema. }\end{array}$ & $\begin{array}{l}\text { Se evidencia claridad, cohe- } \\
\text { rencia y secuencia de ideas } \\
\text { en el tema general y en cada } \\
\text { subtema; se entiende con fa- } \\
\text { cilidad lo que dice. }\end{array}$ \\
\hline \begin{tabular}{|l} 
Ponderación \\
\end{tabular} & 1 & 4 & 6 & 8 \\
\hline $\begin{array}{ll}\text { C6: } & \text { Conclusio- } \\
\text { nes } & \end{array}$ & $\begin{array}{l}\text { No presenta conclu- } \\
\text { siones }\end{array}$ & $\begin{array}{l}\text { Presenta r alguna } \\
\text { conclusión } \\
\text { levante }\end{array}$ & $\begin{array}{l}\text { Presenta conclusio- } \\
\text { nes adecuadas del } \\
\text { tema desarrollado. }\end{array}$ & $\begin{array}{l}\text { Presenta conclusiones claras } \\
\text { y relevantes basada en los } \\
\text { datos o temas presentados } \\
\text { en el trabajo. }\end{array}$ \\
\hline Ponderación & 0 & 2 & 5 & 6 \\
\hline $\begin{array}{l}\mathrm{C}_{7} \text { : Referencias } \\
\text { bibliográficas. }\end{array}$ & $\begin{array}{l}\text { Presenta la bibliogra- } \\
\text { fía sin orden alfabé- } \\
\text { tico. }\end{array}$ & $\begin{array}{l}\text { Presenta las referen- } \\
\text { cias bibliográficas de } \\
\text { los autores citados } \\
\text { en el trabajo, en or- } \\
\text { den alfabético, pero } \\
\text { está incompleto. }\end{array}$ & $\begin{array}{l}\text { Presenta las referen- } \\
\text { cias bibliográficas de } \\
\text { los autores citados } \\
\text { en el trabajo, en or- } \\
\text { den alfabético y está } \\
\text { completo. }\end{array}$ & $\begin{array}{l}\text { Las referencias bibliográfi- } \\
\text { cas están en orden alfabéti- } \\
\text { co, con los datos y formato } \\
\text { sugeridos por APA. Todos los } \\
\text { autores citados están en las } \\
\text { referencias bibliográficas y } \\
\text { todo lo que está en éste han } \\
\text { sido citados en el trabajo. }\end{array}$ \\
\hline Ponderación & 1 & 2 & 3 & 4 \\
\hline
\end{tabular}

Nota: Para el uso del instrumento en el proceso de autoevaluación o coevaluación grupal cambiar el sentido de la redacción de cada descriptor 


\title{
Anexo B: RÚBRICA PARA LA VALORACIÓN DE EXPOSICIONES - DISCUSIONES GRUPALES
}

\author{
Institución: Facultad de Educación - UNCP
}

Escuela profesional:

Asignatura

Semestre:

Docente

Fecha:

Producto a evaluar : Exposición grupal del tema:

\begin{tabular}{|c|c|c|c|c|}
\hline Criterios & En inicio & En avance & Logro aceptable & Logro destacado \\
\hline $\begin{array}{l}\text { C1: Presentación del } \\
\text { grupo }\end{array}$ & $\begin{array}{l}\text { Su presentación es } \\
\text { desordenada y muy } \\
\text { diferenciada. }\end{array}$ & $\begin{array}{l}\text { Algunos buena- } \\
\text { mente presentados } \\
\text { y otros no. }\end{array}$ & $\begin{array}{l}\text { Su presentación gru- } \\
\text { pal es pedagógica- } \\
\text { mente aceptable. }\end{array}$ & $\begin{array}{l}\text { Se evidencia una pre- } \\
\text { sentación coordinada } \\
\text { y conjugada, aceptable } \\
\text { pedagógicamente. }\end{array}$ \\
\hline Ponderación & 0 & 1 & 2 & 3 \\
\hline $\begin{array}{l}\text { C2: Organización y } \\
\text { colaboración grupal }\end{array}$ & $\begin{array}{l}\text { Se muestra desor- } \\
\text { ganización y poca } \\
\text { colaboración de los } \\
\text { integrantes durante } \\
\text { la exposición }\end{array}$ & $\begin{array}{l}\text { Algunos muestran } \\
\text { organización y co- } \\
\text { laboración de los } \\
\text { integrantes duran- } \\
\text { te la exposición }\end{array}$ & $\begin{array}{l}\text { Se muestra organiza- } \\
\text { ción y colaboración } \\
\text { de todos los integran- } \\
\text { tes durante la exposi- } \\
\text { ción. }\end{array}$ & $\begin{array}{l}\text { Se muestra organiza- } \\
\text { ción y colaboración de } \\
\text { todos los integrantes } \\
\text { durante la exposición, } \\
\text { hay ayuda y comple- } \\
\text { mento. }\end{array}$ \\
\hline Ponderación & 1 & 2 & 3 & 4 \\
\hline $\begin{array}{l}\text { C3: Elaboración y uso } \\
\text { de material de exposi- } \\
\text { ción }\end{array}$ & $\begin{array}{l}\text { El material de expo- } \\
\text { sición no es adecua- } \\
\text { do, es poco didác- } \\
\text { tica. }\end{array}$ & $\begin{array}{l}\text { El material de ex- } \\
\text { posición es secuen- } \\
\text { cial, con dificulta- } \\
\text { des en claridad y } \\
\text { didáctica. }\end{array}$ & $\begin{array}{l}\text { El material de exposi- } \\
\text { ción es clara, secuen- } \\
\text { cial y didáctica. }\end{array}$ & $\begin{array}{l}\text { El material de exposi- } \\
\text { ción es clara, secuencial } \\
\text { y didáctica, combina } \\
\text { texto e imagen perti- } \\
\text { nentes. }\end{array}$ \\
\hline Ponderación & 1 & 2 & 3 & 4 \\
\hline $\begin{array}{l}\text { C4: Dominio del tema } \\
\text { en la exposición y dis- } \\
\text { cusión }\end{array}$ & $\begin{array}{l}\text { El grupo no muestra } \\
\text { dominio del tema en } \\
\text { la exposición y ex- } \\
\text { plicación. }\end{array}$ & $\begin{array}{l}\text { El grupo muestra } \\
\text { poco dominio del } \\
\text { tema en la exposi- } \\
\text { ción y explicación. }\end{array}$ & $\begin{array}{l}\text { El grupo muestra do- } \\
\text { minio del tema en la } \\
\text { exposición y explica- } \\
\text { ción de la corriente } \\
\text { epistemológica. }\end{array}$ & $\begin{array}{l}\text { El grupo muestra buen } \\
\text { dominio del tema en la } \\
\text { exposición y explicación } \\
\text { del tema, respuestas } \\
\text { claras a las preguntas. }\end{array}$ \\
\hline Ponderación & 1 & 2 & 4 & 5 \\
\hline $\begin{array}{l}\mathrm{C}_{5} \text { : Capacidad reflexiva } \\
\text { y crítica }\end{array}$ & $\begin{array}{l}\text { No muestra capaci- } \\
\text { dad reflexiva y críti- } \\
\text { ca del tema }\end{array}$ & $\begin{array}{l}\text { Se muestra poca } \\
\text { capacidad reflexiva } \\
\text { y crítica del tema }\end{array}$ & $\begin{array}{l}\text { Se muestra capacidad } \\
\text { reflexiva y crítica del } \\
\text { tema }\end{array}$ & $\begin{array}{l}\text { Se muestra capacidad } \\
\text { reflexiva y crítica del } \\
\text { tema, indicando aportes } \\
\text { y limitaciones con con- } \\
\text { sistencia. }\end{array}$ \\
\hline Ponderación & 1 & 2 & 3 & 4 \\
\hline
\end{tabular}

Nota: Para el uso del instrumento en el proceso de autoevaluación o coevaluación grupal cambiar el sentido de la redacción de cada descriptor. 


\title{
Anexo C: RÚBRICA PARA LA VALORACIÓN DE ENSAYO ACADÉMICO
}

\author{
Institución: Facultad de Educación - UNCP
}

Carrera profesional:

Asignatura:

Título del ensayo:

Autor:

Semestre:

Muestra de desempeño : Ensayo académico

\begin{tabular}{|c|c|c|c|c|}
\hline \multirow{2}{*}{$\begin{array}{l}\text { Indicadores de des- } \\
\text { empeño }\end{array}$} & \multicolumn{4}{|c|}{ Niveles de desempeño } \\
\hline & En inicio & $\begin{array}{c}\text { En proceso de } \\
\text { avance }\end{array}$ & Logro aceptable & Logro Destacado \\
\hline $\begin{array}{l}\text { C1: El título expresa } \\
\text { el contenido del en- } \\
\text { sayo académico. }\end{array}$ & $\begin{array}{l}\text { El título expresa } \\
\text { de manera impre- } \\
\text { cisa el contenido } \\
\text { del ensayo acadé- } \\
\text { mico. }\end{array}$ & $\begin{array}{l}\text { El título expresa } \text { de } \\
\text { manera general } \\
\text { contenido del ensayo } \\
\text { académico. }\end{array}$ & $\begin{array}{l}\text { El título expresa de ma- } \\
\text { nera sintética el conte- } \\
\text { nido del ensayo acadé- } \\
\text { mico. }\end{array}$ & $\begin{array}{l}\text { El título expresa de ma- } \\
\text { nera sintética y clara el } \\
\text { contenido del ensayo } \\
\text { académico. }\end{array}$ \\
\hline Ponderación & 1 & 2 & 3 & 4 \\
\hline $\begin{array}{l}\text { C2: Presenta la es- } \\
\text { tructura básica de } \\
\text { un ensayo académi- } \\
\text { co. }\end{array}$ & \begin{tabular}{|l} 
El ensayo pre- \\
sentar algunos \\
elementos y una \\
estructura simple.
\end{tabular} & $\begin{array}{l}\text { El ensayo presenta } \\
\text { sin mucho orden el tí- } \\
\text { tulo, la introducción, } \\
\text { el contenido, las con- } \\
\text { clusiones y la referen- } \\
\text { cia bibliográfica. }\end{array}$ & $\begin{array}{l}\text { El ensayo presenta de } \\
\text { manera ordenada el tí- } \\
\text { tulo, la introducción, el } \\
\text { contenido, las conclusio- } \\
\text { nes y la referencia biblio- } \\
\text { gráfica. }\end{array}$ & $\begin{array}{l}\text { El ensayo presenta de } \\
\text { manera ordenada y } \\
\text { coherente el título, la } \\
\text { introducción, el conte- } \\
\text { nido, las conclusiones } \\
\text { y la referencia biblio- } \\
\text { gráfica. }\end{array}$ \\
\hline Ponderación & 1 & 2 & 3 & 4 \\
\hline $\begin{array}{l}\text { C3: El ensayo contie- } \\
\text { ne explícitamente } \\
\text { la tesis o idea prin- } \\
\text { cipal. }\end{array}$ & \begin{tabular}{|l} 
Respecto al tema \\
del ensayo, en \\
el desarrollo del \\
contenido no se \\
plantea con clari- \\
dad la tesis o idea \\
principal.
\end{tabular} & $\begin{array}{l}\text { Respecto al tema del } \\
\text { ensayo, en el desarro- } \\
\text { Ilo del contenido se } \\
\text { plantea de modo ge- } \\
\text { nérico la tesis o idea } \\
\text { principal. }\end{array}$ & $\begin{array}{l}\text { Respecto al tema del en- } \\
\text { sayo, en el desarrollo del } \\
\text { contenido se plantea de } \\
\text { modo específico, la tesis } \\
\text { o idea principal. }\end{array}$ & $\begin{array}{l}\text { Respecto al tema del } \\
\text { ensayo, en el desarrollo } \\
\text { del contenido se plan- } \\
\text { tea de modo específico } \\
\text { y con claridad la tesis o } \\
\text { idea principal. }\end{array}$ \\
\hline Ponderación & 1 & 2 & 3 & 4 \\
\hline $\begin{array}{l}\text { C4: Se desarrollan } \\
\text { argumentos que } \\
\text { sustentan la tesis y } \\
\text { proposiciones que } \\
\text { se derivan de ella. }\end{array}$ & \begin{tabular}{|l} 
El ensayo con- \\
tiene escasos \\
argumentos que \\
sustentan la tesis, \\
o proposiciones \\
poco relevantes \\
que se derivan de \\
la tesis.
\end{tabular} & $\begin{array}{l}\text { El ensayo contiene } \\
\text { algunos argumentos } \\
\text { que sustentan la te- } \\
\text { sis, o sólo proposicio- } \\
\text { nes que se derivan de } \\
\text { la tesis. }\end{array}$ & $\begin{array}{l}\text { El ensayo contiene algu- } \\
\text { nos argumentos que sus- } \\
\text { tentan la tesis, así como } \\
\text { proposiciones que se de- } \\
\text { rivan de la tesis. }\end{array}$ & $\begin{array}{l}\text { El ensayo contiene su- } \\
\text { ficientes argumentos } \\
\text { que sustentan la tesis, } \\
\text { así como proposiciones } \\
\text { fundamentales que se } \\
\text { derivan de la tesis. }\end{array}$ \\
\hline Ponderación & 1 & 2 & 3 & 4 \\
\hline $\begin{array}{l}\text { C5: Se plantean las } \\
\text { conclusiones del en- } \\
\text { sayo y la respectiva } \\
\text { referencia bibliográ- } \\
\text { fica. }\end{array}$ & $\begin{array}{l}\text { Se plantean con- } \\
\text { clusiones genéri- } \\
\text { cas e incompleta } \\
\text { referencia biblio- } \\
\text { gráfica. }\end{array}$ & $\begin{array}{l}\text { Se plantean conclu- } \\
\text { siones y la referencia } \\
\text { bibliográfica. }\end{array}$ & $\begin{array}{l}\text { Se plantean conclusiones } \\
\text { precisas y la referencia } \\
\text { bibliográfica. }\end{array}$ & $\begin{array}{l}\text { Se plantean conclu- } \\
\text { siones precisas con } \\
\text { claridad y la referencia } \\
\text { bibliográfica completa. }\end{array}$ \\
\hline Ponderación & 1 & 2 & 3 & 4 \\
\hline
\end{tabular}

Nota: Para el uso del instrumento en el proceso de autoevaluación o coevaluación grupal cambiar el sentido de la redacción de cada descriptor. 


\title{
Anexo D: RÚBRICA PARA LA VALORACIÓN DEL PROYECTO DE TESIS
}

\author{
Institución: Unidad de posgrado Facultad de Educación - UNCP \\ Sección: Maestría ( ) Doctorado ( )
}

Título del proyecto:

Autor/Tesista:.

Mención:

Fecha:

\begin{tabular}{|c|c|c|c|c|}
\hline Criterios & En inicio & En avance & Logro aceptable & Logro destacado \\
\hline C1: Título & $\begin{array}{l}\text { El título expresa la } \\
\text { (s) variables a in- } \\
\text { vestigar en forma } \\
\text { genérica, contiene } \\
\text { más de } 20 \text { palabras. }\end{array}$ & $\begin{array}{l}\text { El título expresa la } \\
\text { (s) variables a inves- } \\
\text { tigar, el sujeto pero } \\
\text { no contexto, entre } \\
15 \text { a } 20 \text { palabras. } \\
\end{array}$ & $\begin{array}{l}\text { El título expresa la } \\
\text { (s) variables a inves- } \\
\text { tigar, sujeto y con- } \\
\text { texto, entre } 13 \text { a } 15 \\
\text { palabras. }\end{array}$ & $\begin{array}{l}\text { El título expresa variables a } \\
\text { investigar, sujeto y contexto, } \\
\text { en promedio de12 palabras } \\
\text { en forma clara y comprensi- } \\
\text { ble. }\end{array}$ \\
\hline \begin{tabular}{|l|} 
Ponderación \\
\end{tabular} & 1 & 2 & 3 & 4 \\
\hline $\begin{array}{l}\text { C2: Desarrollo de } \\
\text { la estructura básica } \\
\text { del proyecto }\end{array}$ & $\begin{array}{l}\text { El proyecto presen- } \\
\text { ta menos del } 50 \% \\
\text { de la estructura bá- } \\
\text { sica. }\end{array}$ & $\begin{array}{l}\text { El proyecto desa- } \\
\text { rrolla gran parte de } \\
\text { la estructura básica } \\
\text { pero no está com- } \\
\text { pleto }\end{array}$ & $\begin{array}{l}\text { El proyecto presenta } \\
\text { toda la estructura } \\
\text { básica en forma ade- } \\
\text { cuada. }\end{array}$ & $\begin{array}{l}\text { El proyecto presenta toda la } \\
\text { estructura básica en forma } \\
\text { adecuada y anexa la matriz } \\
\text { de consistencia. }\end{array}$ \\
\hline \begin{tabular}{|l} 
Ponderación \\
\end{tabular} & 1 & 2 & 3 & 4 \\
\hline $\begin{array}{l}\text { C3: Planteamiento } \\
\text { del problema }\end{array}$ & $\begin{array}{lr}\text { Se desarrolla } & \text { el } \\
\text { planteamiento } & y \\
\text { formulación r del } & \text { problema, y los ob- } \\
\text { jetivos con muchos } \\
\text { desaciertos. }\end{array}$ & $\begin{array}{l}\text { Se desarrolla el } \\
\text { planteamiento y } \\
\text { formulación del pro- } \\
\text { blema, los objetivos } \\
\text { y la justificación con } \\
\text { algunos desacier- } \\
\text { tos. }\end{array}$ & $\begin{array}{l}\text { Se desarrolla el plan- } \\
\text { teamiento y formu- } \\
\text { lación del problema } \\
\text { y los objetivos en } \\
\text { forma aceptable. }\end{array}$ & $\begin{array}{l}\text { Se desarrolla el planteamien- } \\
\text { to del problema en base a } \\
\text { revisión ordenada de fuentes } \\
\text { y antecedentes, se formula el } \\
\text { problema y los objetivos en } \\
\text { forma coherente. }\end{array}$ \\
\hline Ponderación & 1 & 2 & 4 & 8 \\
\hline $\begin{array}{l}\text { C4: Análisis de an- } \\
\text { tecedentes }\end{array}$ & \begin{tabular}{|l} 
Se presenta algunos \\
antecedentes sin \\
comentarios
\end{tabular} & $\begin{array}{l}\text { Se presenta varios } \\
\text { antecedentes con } \\
\text { datos importantes } \\
\text { de cada uno, sin co- } \\
\text { mentarios. }\end{array}$ & $\begin{array}{l}\text { Se presenta varios } \\
\text { antecedentes con } \\
\text { datos relevantes de } \\
\text { cada uno, con un } \\
\text { análisis general. }\end{array}$ & $\begin{array}{l}\text { Se presenta varios antece- } \\
\text { dentes pertinentes con datos } \\
\text { relevantes, agrupados según } \\
\text { criterios y con análisis cohe- } \\
\text { rente, evidenciando aportes, } \\
\text { hallazgos y/o vacíos, presen- } \\
\text { tando el estado del arte. }\end{array}$ \\
\hline ponderación & 2 & 4 & 6 & 8 \\
\hline $\begin{array}{l}\text { C5: Bases teóricas } \\
\text { y definiciones con- } \\
\text { ceptuales }\end{array}$ & $\begin{array}{l}\text { Se desarrolla las ba- } \\
\text { ses teóricas y defi- } \\
\text { niciones sin indicar } \\
\text { fuentes. }\end{array}$ & $\begin{array}{l}\text { Se desarrolla las } \\
\text { bases teóricas y las } \\
\text { definiciones con- } \\
\text { ceptuales aplicando } \\
\text { citas textuales, pero } \\
\text { con algunas incohe- } \\
\text { rencias. }\end{array}$ & $\begin{array}{l}\text { Desarrolla las bases } \\
\text { episte mológicas, } \\
\text { teóricas y las defini- } \\
\text { ciones aplicando ci- } \\
\text { tas textuales y con- } \\
\text { textuales en forma } \\
\text { aceptable. }\end{array}$ & $\begin{array}{l}\text { Desarrolla las bases episte- } \\
\text { mológicas, teóricas y las defi- } \\
\text { niciones basados en fuentes, } \\
\text { conectando las ideas en for- } \\
\text { ma clara y coherente. }\end{array}$ \\
\hline \begin{tabular}{|l|} 
Ponderación \\
\end{tabular} & 2 & 4 & 6 & 8 \\
\hline C6: Hipótesis & $\begin{array}{l}\text { Se evidencia in- } \\
\text { coherencias entre } \\
\text { la hipótesis, el pro- } \\
\text { blema y objetivo. }\end{array}$ & $\begin{array}{l}\text { Se evidencia algu- } \\
\text { nas incoherencias } \\
\text { entre la hipótesis, } \\
\text { el problema y obje- } \\
\text { tivo. }\end{array}$ & $\begin{array}{l}\text { Se evidencia cohe- } \\
\text { rencia entre la hipó- } \\
\text { tesis, el problema y } \\
\text { objetivo, según las } \\
\text { variables a investi- } \\
\text { garse. }\end{array}$ & $\begin{array}{l}\text { Se evidencia claridad y cohe- } \\
\text { rencia entre la hipótesis, el } \\
\text { problema y objetivos, según } \\
\text { las variables o relación de va- } \\
\text { riables asumidas. }\end{array}$ \\
\hline ponderación & 1 & 2 & 4 & 6 \\
\hline C7: Metodología & $\begin{array}{l}\text { Existen muchas in- } \\
\text { coherencias entre el } \\
\text { tipo, método, dise- } \\
\text { ño, muestra, técni- } \\
\text { cas e instrumentos. }\end{array}$ & $\begin{array}{l}\text { Existen algunas in- } \\
\text { coherencias entre el } \\
\text { tipo, método, dise- } \\
\text { ño, muestra, técni- } \\
\text { cas e instrumentos. }\end{array}$ & $\begin{array}{l}\text { Se propone el tipo, } \\
\text { método, diseño, } \\
\text { muestra, técnicas e } \\
\text { instrumentos en for- } \\
\text { ma coherente }\end{array}$ & $\begin{array}{l}\text { Se propone el tipo, método, } \\
\text { diseño, muestra, técnicas e } \\
\text { instrumentos en forma ade- } \\
\text { cuada y coherente, basado } \\
\text { en fuentes y permiten la con- } \\
\text { trastación de las hipótesis. }\end{array}$ \\
\hline Ponderación & 1 & 2 & 3 & 5 \\
\hline
\end{tabular}




\begin{tabular}{|c|c|c|c|c|}
\hline $\begin{array}{l}\text { C8: Referencias bi- } \\
\text { bliográficas. }\end{array}$ & \begin{tabular}{|l|} 
Se presenta una bi- \\
bliografía, muchos \\
no están citados
\end{tabular} & $\begin{array}{l}\text { Las referencias bi- } \\
\text { bliográficas son los } \\
\text { citados, pero no es- } \\
\text { tán en orden alfabé- } \\
\text { tico ni con los datos } \\
\text { exigidos según APA }\end{array}$ & $\begin{array}{l}\text { Las referencias bi- } \\
\text { bliográficas son los } \\
\text { citados, están en or- } \\
\text { den alfabético y con } \\
\text { los datos exigidos } \\
\text { según APA }\end{array}$ & $\begin{array}{l}\text { Las referencias bibliográficas } \\
\text { incluyen fuentes de revistas } \\
\text { indizadas, son los citados, } \\
\text { están en orden alfabético. } \\
\text { Todos los citados están en las } \\
\text { referencias y viceversa. }\end{array}$ \\
\hline Ponderación & 1 & 2 & 3 & 5 \\
\hline $\begin{array}{l}\text { C9: Originalidad// } \\
\text { innovación }\end{array}$ & $\begin{array}{l}\text { El estudio es repeti- } \\
\text { tivo de otros. }\end{array}$ & $\begin{array}{l}\text { Se evidencia el bos- } \\
\text { quejo de un trabajo } \\
\text { nuevo, pero sin refe- } \\
\text { rencia a fuentes, }\end{array}$ & $\begin{array}{l}\text { Especifica lo nuevo } \\
\text { del trabajo por lo } \\
\text { menos en un aspec- } \\
\text { to basado en fuen- } \\
\text { tes y argumentos. }\end{array}$ & $\begin{array}{l}\text { Especifica lo nuevo del tra- } \\
\text { bajo en diversos aspectos } \\
\text { con respecto al estado del } \\
\text { arte, basado en fuentes y } \\
\text { argumentos. El resultado o } \\
\text { producto se puede patentar. }\end{array}$ \\
\hline Ponderación & 1 & 3 & 7 & 10 \\
\hline C10: Pertinencia & $\begin{array}{l}\text { El estudio no res- } \\
\text { ponde a las necesi- } \\
\text { dades o demandas } \\
\text { del contexto actual } \\
\text { o futuro }\end{array}$ & $\begin{array}{l}\text { El estudio responde } \\
\text { de alguna manera } \\
\text { a las necesidades } \\
\text { o demandas del } \\
\text { contexto actual o } \\
\text { futuro }\end{array}$ & $\begin{array}{l}\text { La investigación } \\
\text { responde a necesi- } \\
\text { dades y problemas } \\
\text { del contexto actual, } \\
\text { corroboradas en di- } \\
\text { versas fuentes. }\end{array}$ & $\begin{array}{l}\text { La investigación responde } \\
\text { a necesidades, problemas o } \\
\text { demandas urgentes del con- } \\
\text { texto actual y futuro, corro- } \\
\text { boradas en datos y fuentes. }\end{array}$ \\
\hline Ponderación & 1 & 3 & 4 & 6 \\
\hline $\begin{array}{l}\text { C11: Relevancia y } \\
\text { aportes }\end{array}$ & $\begin{array}{l}\text { No se evidencia re- } \\
\text { levancia ni aportes } \\
\text { significativos en el } \\
\text { ámbito regional y } \\
\text { nacional. }\end{array}$ & $\begin{array}{l}\text { Se evidencia poca } \\
\text { relevancia y aportes } \\
\text { en el ámbito regio- } \\
\text { nal y nacional, en la } \\
\text { línea de investiga- } \\
\text { ción. }\end{array}$ & $\begin{array}{l}\text { Se evidencia que la } \\
\text { investigación será } \\
\text { relevante y precisa } \\
\text { algunos aportes en } \\
\text { el ámbito regional y } \\
\text { nacional. }\end{array}$ & $\begin{array}{l}\text { La investigación será rele- } \\
\text { vante con aportes significati- } \\
\text { vos en el ámbito regional y/o } \\
\text { nacional, enmarcado en una } \\
\text { línea de investigación nacio- } \\
\text { nal o internacional. }\end{array}$ \\
\hline Ponderación & 0 & 3 & 7 & 10 \\
\hline $\begin{array}{l}\text { C12: Claridad y co- } \\
\text { herencia }\end{array}$ & $\begin{array}{l}\text { Se nota confusiones } \\
\text { e incoherencias en } \\
\text { muchos aspectos } \\
\text { del proyecto. }\end{array}$ & $\begin{array}{l}\text { Se evidencia poca } \\
\text { claridad y coheren- } \\
\text { cia entre los compo- } \\
\text { nentes básicos del } \\
\text { proyecto. }\end{array}$ & $\begin{array}{l}\text { Se evidencia clari- } \\
\text { dad y coherencia } \\
\text { entre los compo- } \\
\text { nentes básicos del } \\
\text { proyecto. }\end{array}$ & $\begin{array}{l}\text { Se evidencia claridad en to- } \\
\text { das sus partes y guarda cohe- } \\
\text { rencia entre los componen- } \\
\text { tes del proyecto }\end{array}$ \\
\hline Ponderación & 1 & 3 & 4 & 6 \\
\hline
\end{tabular}

Mi reflexión metacognitiva: ¿Cuáles son mis fortalezas y debilidades, en qué aspecto necesito apoyo/orientación, ¿qué debo hacer para superar las debilidades?

\section{Mi compromiso de mejora:}




\title{
Anexo E: RÚBRICA PARA LA VALORACIÓN DEL ARTÍCULO ACADÉMICO
}

\author{
Institución: Unidad de posgrado Facultad de Educación - UNCP \\ Sección: Maestría ( ) Doctorado
}

Título del artículo:

Autor/Tesista:.

Fecha:

Muestra de desempeño: Artículo académico

\begin{tabular}{|c|c|c|c|c|}
\hline \multirow{2}{*}{$\begin{array}{l}\text { Indicadores de des- } \\
\text { empeño }\end{array}$} & \multicolumn{4}{|c|}{ Niveles de desempeño } \\
\hline & En inicio & $\begin{array}{c}\text { En proceso de } \\
\text { avance }\end{array}$ & Logro aceptable & Logro Destacado \\
\hline $\mathrm{C}_{1}$ : Título sintético & $\begin{array}{l}\text { El título expresa el } \\
\text { tema/variable inves- } \\
\text { tigada, en forma ge- } \\
\text { nérica y con muchas } \\
\text { palabras. }\end{array}$ & \begin{tabular}{|l} 
El título expresa el \\
tema/variable in- \\
vestigada, en más \\
de 12 palabras.
\end{tabular} & $\begin{array}{l}\text { El título expresa el } \\
\text { tema/variable inves- } \\
\text { tigada, en forma sin- } \\
\text { tética, en promedio } \\
\text { de } 12 \text { palabras. } \\
\end{array}$ & $\begin{array}{l}\text { El título expresa el tema/ } \\
\text { variable investigada, en } \\
\text { forma sintética y clara, en } \\
\text { no más de } 12 \text { palabras. }\end{array}$ \\
\hline Ponderación & 1 & 2 & 3 & 4 \\
\hline $\begin{array}{l}\text { C2: Desarrolla la es- } \\
\text { tructura básica }\end{array}$ & $\begin{array}{l}\text { El artículo presenta el } \\
\text { título, y el desarrollo } \\
\text { temático, con biblio- } \\
\text { grafía, es muy volu- } \\
\text { minoso o demasiado } \\
\text { pobre. }\end{array}$ & $\begin{array}{l}\text { El artículo presenta } \\
\text { el título, el autor, } \\
\text { la introducción, el } \\
\text { desarrollo temáti- } \\
\text { co, y las referencias } \\
\text { bibliográficas }\end{array}$ & $\begin{array}{l}\text { El artículo presen- } \\
\text { ta el título, autor, } \\
\text { resumen, abstract, } \\
\text { palabras claves, la } \\
\text { introducción, el de- } \\
\text { sarrollo temático y } \\
\text { las referencias bi- } \\
\text { bliográficas. }\end{array}$ & $\begin{array}{l}\text { Presenta el título, autor y } \\
\text { su filiación institucional, } \\
\text { resumen, abstract, palabras } \\
\text { claves, la introducción, el } \\
\text { desarrollo temático, la dis- } \\
\text { cusión/conclusiones y las } \\
\text { referencias bibliográficas. }\end{array}$ \\
\hline Ponderación & 1 & 2 & 3 & 4 \\
\hline $\begin{array}{l}\text { C3: Presenta el re- } \\
\text { sumen y abstract. }\end{array}$ & $\begin{array}{l}\text { Presenta el resumen, } \\
\text { pero no el abstract. }\end{array}$ & $\begin{array}{l}\text { Presenta el resu- } \\
\text { men y el abstract, } \\
\text { pero está incom- } \\
\text { pleta o inadecuada, } \\
\text { elementos sueltos. }\end{array}$ & $\begin{array}{l}\text { El resumen y abs- } \\
\text { tract presenta sin- } \\
\text { téticamente el con- } \\
\text { tenido y propuesta } \\
\text { aporte del artículo, } \\
\text { los conceptos claves. }\end{array}$ & $\begin{array}{l}\text { El resumen presenta sinté- } \\
\text { ticamente el contenido, in- } \\
\text { tención y propuesta/aporte } \\
\text { del artículo, los conceptos } \\
\text { claves. El abstract es cohe- } \\
\text { rente al resumen. }\end{array}$ \\
\hline & 1 & 2 & 3 & 4 \\
\hline $\begin{array}{l}\text { C4: Introducción } \\
\text { presenta las bases } \\
\text { teóricas, epistémi- } \\
\text { cas y antecedentes } \\
\text { articuladas. }\end{array}$ & $\begin{array}{l}\text { El desarrollo de las } \\
\text { bases teóricas del ar- } \\
\text { tículo presenta el de- } \\
\text { sarrollo temático sin } \\
\text { aplicar normas de re- } \\
\text { dacción internacional. }\end{array}$ & $\begin{array}{l}\text { Presenta los ante- } \\
\text { cedentes y el marco } \\
\text { conceptual con po- } \\
\text { cas citas, aplicando } \\
\text { normas de redac- } \\
\text { ción internacional. } \\
\end{array}$ & $\begin{array}{l}\text { Presenta los ante- } \\
\text { cedentes y el marco } \\
\text { conceptual con citas, } \\
\text { aplicando normas de } \\
\text { redacción interna- } \\
\text { cional. }\end{array}$ & $\begin{array}{l}\text { Presenta el desarrollo de } \\
\text { los fundamentos epistemo- } \\
\text { lógicos, los antecedentes } \\
\text { y el marco conceptual en } \\
\text { base a fuentes interrelacio- } \\
\text { nadas y comentadas. }\end{array}$ \\
\hline Ponderación & 1 & 3 & 5 & 8 \\
\hline $\begin{array}{l}\text { C5: Planteamientos } \\
\text { de tesis y argumen- } \\
\text { tos }\end{array}$ & $\begin{array}{l}\text { No se plantea con cla- } \\
\text { ridad la tesis o idea } \\
\text { principal. }\end{array}$ & $\begin{array}{l}\text { Se plantea de modo } \\
\text { genérico la tesis o } \\
\text { idea principal. }\end{array}$ & \begin{tabular}{|l|} 
Se plantea de modo \\
específico la tesis o \\
idea principal y sus \\
argumentos básicos.
\end{tabular} & $\begin{array}{l}\text { Se plantea de modo espe- } \\
\text { cífico y con claridad la tesis } \\
\text { o idea principal y los argu- } \\
\text { mentos claros. }\end{array}$ \\
\hline Ponderación & 1 & 3 & 5 & 8 \\
\hline $\begin{array}{l}\text { C6: Discusión y/o } \\
\text { conclusiones. }\end{array}$ & $\begin{array}{l}\text { No presenta discu- } \\
\text { sión ni conclusiones. }\end{array}$ & $\begin{array}{l}\text { Se hace una discu- } \\
\text { sión general pero } \\
\text { no se presenta con- } \\
\text { clusiones }\end{array}$ & $\begin{array}{l}\text { Se hace una discu- } \\
\text { sión del tema/pro- } \\
\text { blema, según enfo- } \\
\text { ques, corrientes y un } \\
\text { punto de vista asu- } \\
\text { mido o propuesto. } \\
\end{array}$ & $\begin{array}{l}\text { Se hace una discusión del } \\
\text { tema/problema, según } \\
\text { enfoques, corrientes y un } \\
\text { punto de vista asumido } \\
\text { o propuesto. Se presenta } \\
\text { conclusiones. }\end{array}$ \\
\hline Ponderación & 1 & 2 & 4 & 6 \\
\hline $\begin{array}{ll}\text { C7: } & \text { Referencias } \\
\text { bibliográficas } & \text { com- } \\
\text { pletas } & \end{array}$ & $\begin{array}{l}\text { Se presenta una bi- } \\
\text { bliografía general sin } \\
\text { orden. }\end{array}$ & $\begin{array}{l}\text { Las referencias bi- } \\
\text { bliográficas son los } \\
\text { citados, pero no es- } \\
\text { tán en orden. }\end{array}$ & $\begin{array}{l}\text { Las referencias bi- } \\
\text { bliográficas son los } \\
\text { citados, están en or- } \\
\text { den alfabético y con } \\
\text { los datos exigidos. }\end{array}$ & $\begin{array}{l}\text { Las referencias bibliográ- } \\
\text { ficas son los citados, están } \\
\text { en orden alfabético y con } \\
\text { los datos exigidos. Todos } \\
\text { los citados están en las re- } \\
\text { ferencias y viceversa. }\end{array}$ \\
\hline Ponderación & 1 & 2 & 4 & 6 \\
\hline
\end{tabular}

